\title{
Aporte de Serrapilheira ao Solo em Estágios Sucessionais Florestais na Reserva Biológica de Poço das Antas, Rio de JANEIRO, BrasiL
}

\author{
Jose Henrique Cerqueira Barbosa ${ }^{1}$ \& Sérgio Miana de Faria ${ }^{2}$
}

\section{RESUMO}

(Aporte de serrapilheira ao solo em estágios sucessionais florestais na Reserva Biológica de Poço das Antas, Rio de Janeiro,Brasil) Foram definidos mosaicos de fitofisionomias temporais em sistemas tropicais de baixada localizados na REBIO de Poço das Antas, RJ - Brasil. A serrapilheira foi quantificada com coletas quinzenais e determinada sua concentração de nutrientes via fração foliar em intervalos bimestrais. A floresta avançada apresentou o maior aporte de $6,9 \pm 1,1$ ton ha ${ }^{-1}$ ano $^{-1}$ total, o estágio intermediário com $5,5 \pm 0,5$ ton ha ${ }^{-1}$ ano ${ }^{-1}$ total e para o plantio $3 \pm 0,7$ ton ha ${ }^{-1}$ ano ${ }^{-1}$ total. As concentrações via serrapilheira (fração foliar) dos nutrientes $\mathrm{N}, \mathrm{P}$, $\mathrm{Ke}$ Ca foram maiores com o uso de Mimosa bimucronata (DC.) O. Kuntze nos reflorestamentos, demostrando ser esta uma espécie de potencial elevado quanto ao conteúdo nutricional à recomposição de ecossistemas. Sua estratégia de renovação foliar ocorre sob o ritmo perenifólio, com maior contribuição na estação chuvosa e sincronizado a fase reprodutiva. A magnitude de transferência dos nutrientes na fração foliar para os estágios estudados segue a ordem de concentração: $\mathrm{P}<\mathrm{K}<\mathrm{Mg}<\mathrm{Ca}<\mathrm{N}<\mathrm{C}$. Não foram encontradas diferenças significativas quanto as concentrações de entrada dos nutrientes entre as estações nos estágios estudados. Palavras-chave: Serrapilheira, floresta tropical, Mata Atlântica, nutrientes e Mimosa bimucronata.

\section{Abstract}

(Litter-fall input on sucessional forest gaps of temporal fitofisionoms on Biological Reserve of Poço das Antas, Rio de Janeiro, Brazil) Gaps of temporal fitofisionoms were defined on lowland tropical systems localized in the Biologic Reserve of Poço das Antas RJ - Brazil. The litter-fall was quantificated by each fifteen days and was determinated the nutrient concentration of foliar fraction each two months. The oldest forest had the major litter-fall, 6.911 .1 ton $^{-1}{ }^{-1}$ year $^{-1}$ total as the other fractions, when compared with the intermediate age forest with 5.5 10.5 ton $^{-1} \mathrm{year}^{-1}$ total. The plantation had the lowest values, 3.010 .7 ton $\mathrm{ha}^{-1}$ year ${ }^{-1}$ total. The foliar litter-fall concentration of N, P, K, Ca nutrients were bigger for Mimosa bimucronata (DC.) O. Kuntze crop, showing then the great ecosystems nutritional recomposition potential of this specie with foliar renovation strategy occurs under perenifolial rhythm, mostly in the rain season synchronized to the reproduction phase. The transference rate of the nutrients in the studied foliar fraction follows this concentration order: $\mathrm{P}<\mathrm{K}<\mathrm{Mg}<\mathrm{Ca}<\mathrm{N}<\mathrm{C}$.

Key words: Litter-fall, tropical forest, Atlantic Forest, nutrients, and Mimosa bimucronata.

\section{INTRODUÇÃO}

Compreender os processos dinâmicos que envolvem a matéria orgânica do solo entre diferentes estágios sucessionais florestais, representa de forma valiosa, investigar o complexo e necessário rumo a obtenção de medidas mitigadoras que atendam a relação custo $\mathrm{x}$ benefício para os sistemas explorados e impactados sob diferentes graus de perturbação pelo "Homem Moderno" (Franco \& Campello
1997). A utilização de técnicas de plantio é uma medida mitigatória e que devidamente estudada, pode atender a opção de baixo custo e ser ecologicamente funcional, visando a recuperação de áreas impactadas.

A serrapilheira constitui-se de matéria orgânica de origem vegetal e animal que é depositada sobre o solo, sob diferentes estágios de decomposição, representando assim, uma forma de entrada e posterior incremento da matéria orgânica do solo.

Artigo recebido em 02/2005. Aceito para publicação em 01/2006.

${ }^{1}$ UFRRJ - Instituto de Agronomia - Depto. Solos, km 47 da antiga rodovia Rio-São Paulo, Itaguaí, RJ, 23851-970; josehenrique.barbosa@mma.gov.br

${ }^{2}$ EMBRAPA/Agrobiologia, Cx. postal 74.505, km 47 da antiga rodovia Rio-São Paulo, Itaguaí, RJ, 23851-970, sdefaria@cnpab. 
A matéria orgânica controla muitas das propriedades físicas, químicas e biológicas do solo, caracterizando-se como um fator-chave à manutenção de sistemas florestais e controle de processos erosivos, como o fornecimento de substâncias agregantes ao solo, determinando uma estrutura mais estável à ação das chuvas (Facelli \& Pickett 1991).

A acumulação de serrapilheira intercepta luz, sombreando sementes e plântulas e reduzindo a amplitude térmica do solo. Ao reduzir a tempertatura do solo e ao criar uma barreira à difusão do vapor d'água, a serrapilheira reduz a evaporação do solo. Ao contrário, pode também reduzir a disponiblidade de água, retendo uma considerável proporção de água da chuva que chegaria ao solo. Pode ainda impedir a chegada de algumas sementes e dificultar o crescimento de plântulas (Facelli \& Pickett 1991).

Florestas tropicais conseguem crescer em substratos pobres em nutrientes somente a partir da manutenção dos mesmos sob altos níveis de biomassa, através de mecanismos de conservação, produzindo um ciclo de nutrientes relativamente otimizador ou fechado com pequenas quantidades (Herrera et al. 1978). Florestas as quais crescem em substratos mais férteis, exibem ciclos de nutrientes mais dinâmicos (Baillie 1989). Plantios florestais ou recentes florestas secundárias, geralmente representam ecossistemas em crescimento na formação da taxa de entrada de nutrientes via decomposição da serrapilheira, suplementada pela deposição seca e úmida; necessárias para a manutenção do bioma (Bruijnzeel 1989 apud Bruijnzeel 1991).

Os nutrientes entram no sistema através da chuva (deposição úmida), deposição de poeira, aerossóis e serrapilheira (deposição seca), pela fixação do nitrogênio por meio de microrganismos e exceto ao mesmo, pelo intemperismo de rochas. E a exportação, através da lixiviação (escorrimento superficial), volatilização via combustão da biomassa e tantas outras formas de erosão (Vitousek \& Sanford 1986). O maior reservatório de nutrientes sobre o solo é a biomassa epígea (Andrade 1997; Myers et al. 1994; Proctor 1987; Rosén 1990 e Schlittler 1990). Porém para biomas como o cerrado a maior biomassa se encontra como hipógea.

Quando a entrada de nutrientes via serrapilheira localizados na fração foliar sob florestas que se apresentem a partir do estágio médio de recomposição vegetal, demonstra ser de menor conteúdo nutricional ao mesmo tempo que o solo apresenta menores estoques. É esperado que a vegetacão realize uma economia de nutrientes como medida compensatória. $\mathrm{Ou}$, exporte uma serrapilheira com características de maior velocidade de decomposição sobre o solo, a fim de torná-los prontamente disponíveis, quanto mais avançado e complexo for o sistema. Numa outra visão, pode ser esperado que o material de menor velocidade de decomposição represente uma estratégia contra os processos lixiviadores dos nutrientes. Será que podemos até o momento analisar a superioridade ou a independência de um fator sobre o outro? A necessidade de associarmos e entendermos os efeitos sinergéticos demonstrados pela complexidade dos diferentes eventos dinâmicos que atuam na ciclagem biogeoquímica da matéria orgânica do solo, em especial à serrapilheira; pode ser compreendida como base na recuperação e manutenção de ecossistemas florestais, utilizada como diferentes estratégias mitigadoras implantadas em projetos conservacionistas e/ou de recuperação; a fim de permitir uma resposta mais rápida frente aos problemas potenciais de degradação, que rapidamente estão destruindo os ecossistemas do bioma Mata Atlântica sem um conhecimento prévio de parâmetros indispensáveis a seu adequado manejo.

As formações vegetacionais de baixada na REBIO de Poço das Antas, representam um valioso centro de estudos para a Floresta Atlântica. Nesta área conservada e protegida, 
a escolha dos fragmentos florestais se deu através dos pré-requisitos: a) atender de forma prática e segura a tomada dos resultados, b) representar estágios sucessionais florestais bastante característicos dos ecossistemas ameaçados do bioma mata atlântica e, c) ser protegida por legislação ambiental específica; representando assim sítios de estudos prioritários.

Para averiguar a entrada de serrapilheira e seu conteúdo nutricional, foram determinados os objetivos:

(1) Investigar a produção de serrapilheira total e de suas frações isoladas, como folhas, galhos, material reprodutivo e refugo e

(2) Análise dos macronutrientes: C, N, P, $\mathrm{K}, \mathrm{Ca}$ e $\mathrm{Mg}$ e relação $\mathrm{C} / \mathrm{N}$ na fração foliar da serrapilheira aportada.

\section{Material e Métodos}

\section{Área de estudo}

A área de estudo encontra-se na Reserva Biológica de Poço das Antas (REBIO), localizada no município de Silva Jardim $\left(22^{\circ} 30^{\prime}\right.$ e $22^{\circ} 33^{\prime} \mathrm{S}, 42^{\circ} 15^{\prime}$ e $42^{\circ} 19^{\prime} \mathrm{W}$ ), estado do Rio de Janeiro, com área de 5.267 ha (IBDF 1981), situada em extensa planície. Os diferentes estágios florestais estudados perfazem juntos aproximadamente um terço da Reserva.
Os fragmentos representam formações florestais secundárias de 40 anos e outra de 20 sob solo Hidromórfico cinzento álico textura argilosa - Glei Húmico. E ainda como estágio inicial um campo antrópico com plantio misto de três anos sob solo aluvial álico textura argilosa, onde foi acompanhado o aporte específico de Maricá, Mimosa bimucronata (DC.) O. Kuntze Leguminosae Mimosoideae.

\section{Clima}

De acordo com a classificação de Thornthwaite (1948), o clima é do tipo A' B2, megatérmico, úmido, sem déficit hídrico; com índice de evapotranspiração potencial superior a $1.140 \mathrm{~mm} \mathrm{~A}^{\prime}$, umidade efetiva de 51,5 (B2) e o índice de aridez de 0,072 (r). A comunidade vegetal passa de janeiro até junho por excedente hídrico de $460 \mathrm{~mm}$ e $250 \mathrm{~mm}$ a partir de meados de agosto até dezembro. Nos meses de menor precipitação de junho a agosto, apesar da evapotranspiração real ser praticamente idêntica a evapotranspiração potencial, há retirada d'água de $23 \mathrm{~mm}$ no solo, havendo uma deficiência no mês de agosto, em que a precipitação-evapotranspiração resultou em um valor de (-17), alterando em $1 \mathrm{~mm}$ de evapotranspiração real. Estes

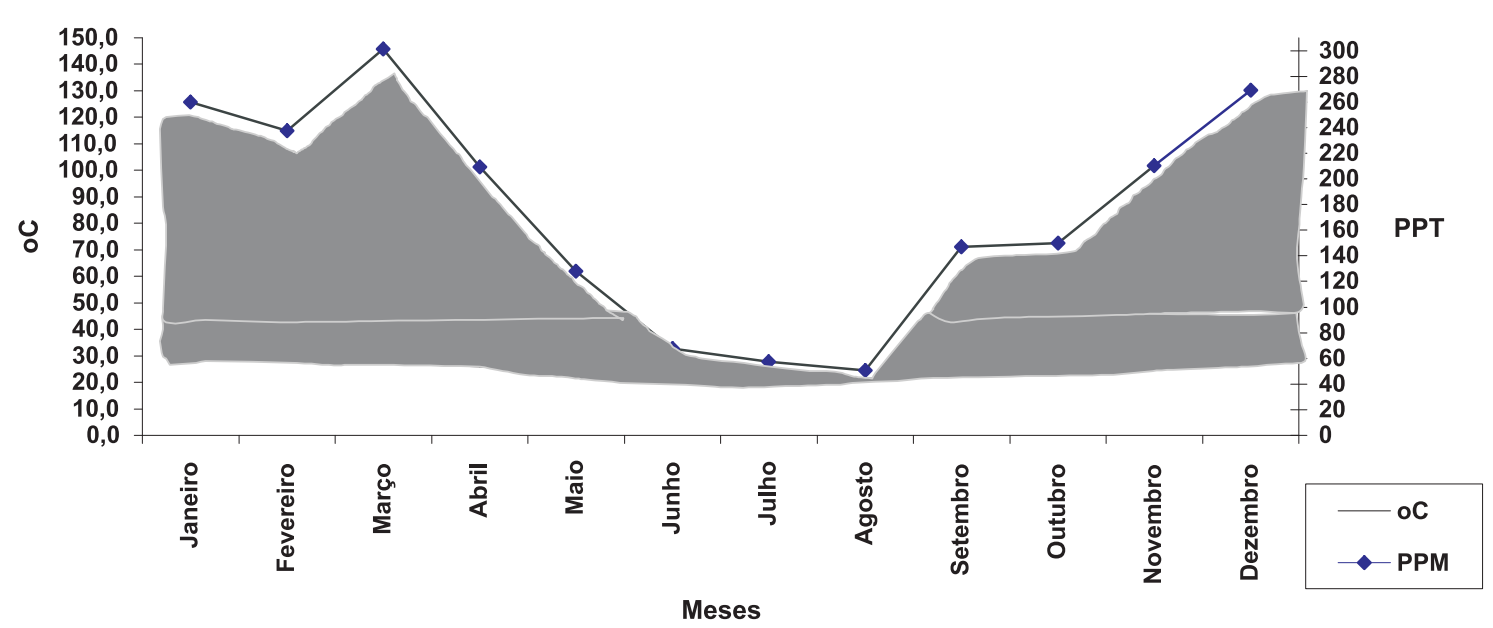

Figura 1 - Diagrama climático entre janeiro de 1987 a dezembro de 1997 (11 anos) da REBIO de Poço das Antas. 
resultados sugerem um pequeno déficit hídrico nesse mês, sem estação seca definida, havendo uma reposição de $23 \mathrm{~mm}$ neste mesmo mês. O valor final da evapotranspiração potencial é de $1.378 \mathrm{~mm}$ e evapotranspiração real de $1.377 \mathrm{~mm}$. Denotando-se um decréscimo na curva de precipitação no período de junho a agosto, o que não chega a ser considerado um período seco.

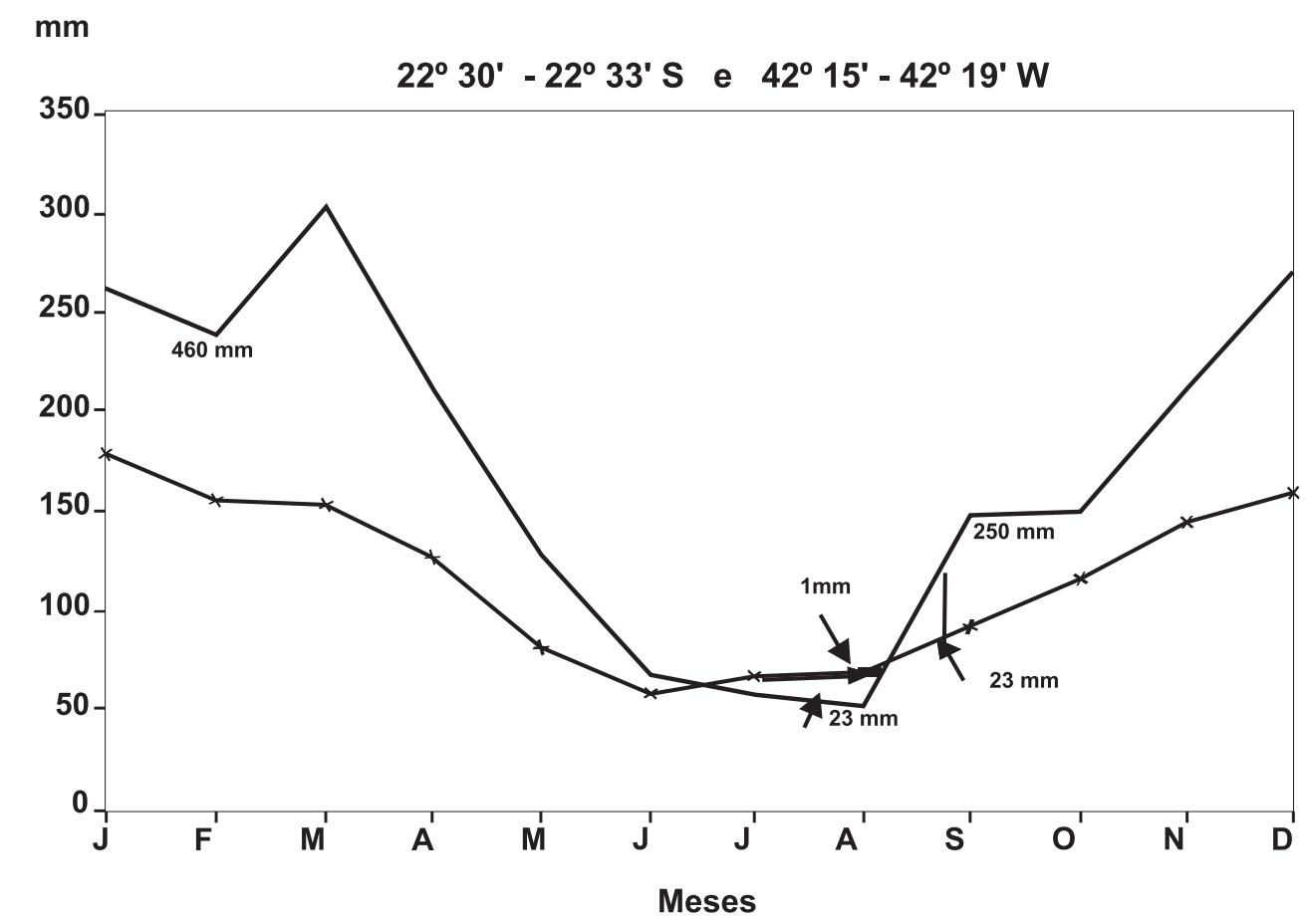

Figura 2 - Balanço hídrico entre janeiro de 1987 a dezembro de 1997 (11 anos) da REBIO de Poço das Antas.

\section{Coletas de Serrapilheira}

Cinco coletores de serrapilheira com dimensões de $50 \mathrm{~cm} \times 50 \mathrm{~cm}$ foram alocados aleatoriamente em três parcelas $(25 \mathrm{~m} \times 50$ $\mathrm{m})$, totalizando 15 para cada área. Após a coleta quinzenal o material foi seco em estufa a $70{ }^{\circ} \mathrm{C}$ durante 24 horas. Depois triado em galhos, folhas, material reprodutivo composto por: frutos, sementes e flores e por último o refugo (material $\leq 2 \mathrm{~mm}$ de diâmetro de difícil identificação). Em seguida o material triado foi pesado e triturado em moinho tipo Wiley com malha $\leq 2 \mathrm{~mm}$ de diâmetro.

\section{Análises Químicas}

A análise química através de digestão nitro-perclórica dos nutrientes presentes na fração foliar da serrapilheira, seguiu os métodos: $\mathrm{P}$ por espectrofotômetro de cor visível (Bataglia et al. 1983); K por fotometria de chama (Tedesco et al. 1985 apud Hungria et al. 1994); Ca e Mg através de espectrofotômetro de absorção atômica (Bataglia et al. 1983); C, método de Combustão Seca, utilizado pelo Ministério da Agricultura (EMBRAPA - SNLCS 1979) e N, método semimicro de Kjeldahl (Jones 1991; Bataglia et al. 1983 \& Bremmer 1965). As análises estatísticas foram realizadas com o auxílio do Programa SAEG 50 da Fundação Arthur Bernardes - UFV. 


\section{Resusltados e Discussão \\ Dados climáticos}

Abril de 1996 a março de 1997 - O mês de julho demonstrou a menor temperatura média, com $20,2^{\circ} \mathrm{C}$ e a menor pluviosidade de $33,9 \mathrm{~mm}$ foi registrada no mês de junho. Enquanto a maior média foi encontrada para o mês de fevereiro, $30,8^{\circ} \mathrm{C}$ e o maior índice pluviométrico de $476,6 \mathrm{~mm}$ em janeiro.
A temperatura média de $25,4^{\circ} \mathrm{C}$ e o índice pluviométrico anual de $2.231 \mathrm{~mm}$ identificados no ano de estudo, não apresentaram diferença significativa quando comparado aos demais anos da série temporal de 10 anos entre abril de 1987 a março de 1997, ao serem analisados pelo teste Tukey a 5\% de significância, com a média pluviométrica de $2.131 \mathrm{~mm}$ e temperatura média de $24,6^{\circ} \mathrm{C}$. Demonstrando ser o ano estudado, um ano típico (Tabelas 1a e 1b).

Tabela1a - Valores médios entre abril de 1996 a março de 1997 para temperatura mínima, média e máxima, bem como precipitação total.

\begin{tabular}{|c|c|c|c|c|c|c|c|c|c|c|c|c|c|c|}
\hline & Abr & Mai & Jun & Jul & Ago & Set & Out & Nov & Dez & Jan & Fev & Mar & Anual média & $\mathrm{cV} \%$ \\
\hline${ }^{\circ} \mathrm{C}$ mínima & 19.3 & 17.0 & 14.7 & & 15.1 & 16.4 & 18.9 & 19.3 & 20.5 & 21.2 & 21.6 & 20.0 & $\mathbf{1 8 , 2}+-1,6$ & 14,1 \\
\hline${ }^{\circ} \mathrm{C}$ média & 27.1 & 23.6 & 22.2 & 20.2 & 21.4 & 22.8 & 25.6 & 26.2 & 28.8 & 28.8 & 30.8 & 27.5 & $25,4+-2,1$ & 13,2 \\
\hline \multirow[t]{2}{*}{${ }^{\circ} \mathrm{C}$ máxima } & 34.8 & 26.3 & 25.9 & 25.1 & 26.5 & 27.0 & 28.7 & 29.9 & 30.1 & 36.3 & 39.9 & 35.0 & $\mathbf{3 0 , 5}+-3,1$ & 16 \\
\hline & & & & & & & & & & & & & Total anual & \\
\hline ppt & 143.9 & 132.5 & 33.9 & 51.2 & 59.6 & 215.2 & 114.9 & 372.7 & 321 & 476.6 & 71.2 & 238.5 & $2.231,2$ & 76,3 \\
\hline
\end{tabular}

Valores médios anuais a partir de 12 repetições, erro-padrão (t- Student) com $\mathrm{p} \leq$ 0,05 e cv \% entre as temperaturas e precipitações mensais. Os valores assinalados indicam a mínima e a máxima encontradas.
Valores médios anuais a partir de 10 repetições, erro-padrão (t- Student) com $\mathrm{p} \leq 0,05$ e cv \% entre as temperaturas e precipitações anuais. Os valores assinalados indicam a mínima e a máxima encontradas.

Tabela 1b - Valores médios entre a série temporal de abril de 1987 a março de 1997 (10 anos) para temperatura mínima, média e máxima, bem como precipitação total média.

\begin{tabular}{ccccccccccccccc}
\hline & Abr & Mai & Jun & Jul & Ago & Set & Out & Nov & Dez & Jan & Fev & Mar & Anual média & cv \% \\
\hline${ }^{\circ} \mathrm{C}$ mínima & 20.1 & 17.0 & 14.7 & $\mathbf{1 4 . 5}$ & 15.1 & 16.4 & 18.9 & 19.3 & 20.5 & 21.8 & $\mathbf{2 2 . 2}$ & 21.3 & $\mathbf{1 8 , 5 + -} 0,6$ & 16,5 \\
${ }^{\circ} \mathrm{C}$ média & 26.1 & 22.6 & $\mathbf{2 0 . 4}$ & 21.0 & 21.2 & 22.7 & 24.6 & 25.8 & 26.6 & 28.3 & $\mathbf{2 8 . 6}$ & 27.3 & $\mathbf{2 4 , 6 + -} 0,7$ & 13 \\
${ }^{\circ} \mathrm{C}$ máxima & 30.9 & 26.3 & 25.9 & $\mathbf{2 5 . 1}$ & 26.5 & 27.0 & 28.7 & 29.9 & 30.1 & 34.5 & $\mathbf{3 5 . 5}$ & 32.6 & $\mathbf{2 9 , 4}+-1,4$ & 13,9 \\
\hline & & & & & & & & & & & & & Total anual média \\
ppt & 211.4 & 137.1 & 73.2 & 61.9 & $\mathbf{4 6 . 1}$ & 155.7 & 151.6 & 210.3 & 269.4 & 265.5 & 240.7 & $\mathbf{3 0 8 . 1}$ & $\mathbf{2 . 1 3 1 , 1 + - 2 0 6}$ & 66,5 \\
\hline
\end{tabular}

\section{Aporte}

A quantificação da serrapilheira aportada ao solo foi verificada quanto aos valores separados por frações e estágios florestais, e os mesmos são apresentados na Tabela 2.
Estimativa da média a partir de 15 amostras, seu erro-padrão ( $\mathrm{t}$ - Student) com $\mathrm{p}$ $\leq 0,05$ e teste Tukey a $5 \%$ de significância entre os estágios. Letras diferentes indicam diferença significativa e cv \% entre os estágios para cada fração através da Anova. 
Tabela 2 - Aporte de serrapilheira em $\mathrm{kg} \mathrm{ha}^{-1}$ ano $^{-1}$ para os diferentes estágios sucessionais durante abril de 1996 a março de 1997, na REBIO de Poço das Antas.

\begin{tabular}{|c|c|c|c|c|c|c|}
\hline \multicolumn{7}{|c|}{ BIOMASSA - SERRAPILHEIRA } \\
\hline \multirow[t]{2}{*}{ Área } & Idade & Folhas & Galhos & $\begin{array}{l}\text { Material Reprodutivo } \\
\text { (flores, frutos e sementes) }\end{array}$ & Refugo & Aporte Total \\
\hline & Anos & & & $\mathrm{Kg} \mathrm{ha}^{-1} \mathrm{ano}^{-1}$ & & \\
\hline FLORESTA & 40 & $4.980,0 \pm 649,5 a$ & $1.255,8 \pm 399,1 a$ & $\mathbf{3 2 8 , 2} \pm 119,2 \mathbf{b}$ & $310,2 \pm 94,5 \mathbf{a}$ & $\mathbf{6 . 8 7 4 , 3} \pm 1.070,8 \mathrm{a}$ \\
\hline FLORESTA & 20 & $3.645,0 \pm 368,8 b$ & $987,2 \pm 320,2 a$ & $634,3 \pm 200,2 a$ & $212,7 \pm 36,4$ b & $5.479,2 \pm 520,5$ b \\
\hline \multirow[t]{2}{*}{ PLANTIO } & 3 & $\mathbf{2 . 1 9 2 , 4} \pm 507,4 \mathrm{c}$ & $\mathbf{5 0 4 , 4} \pm 114,6 \mathbf{b}$ & $81,7 \pm 25,7 c$ & $\mathbf{2 4 7 , 0} \pm 167,4 \mathbf{a}$ & $\mathbf{3 . 0 2 5 , 5} \pm 738,4 \mathrm{c}$ \\
\hline & CV \% & 25,5 & 18,9 & 44,1 & 22,5 & 29,1 \\
\hline
\end{tabular}

Pela Tabela 2 verifica-se que as contribuições para as diferentes frações retornadas ao solo via serrapilheira em $\%$ e biomassa para a floresta avançada foram: $72,4 \%\left(4.980,0 \mathrm{~kg} \mathrm{ha}^{-1} \mathrm{ano}^{-1}\right)$ para a fração foliar, $18,3 \%\left(1.255,8 \mathrm{~kg} \mathrm{ha}^{-1} \mathrm{ano}^{-1}\right)$ galhos,
$4,8 \%\left(328,2 \mathrm{~kg} \mathrm{ha}^{-1} \mathrm{ano}^{-1}\right)$ material reprodutivo e $4,5 \%\left(310,2 \mathrm{~kg} \mathrm{ha}^{-1} \mathrm{ano}^{-1}\right)$ refugo. O aporte total foi de $6.874,3 \mathrm{~kg} \mathrm{ha}^{-1}$ $\mathrm{ano}^{-1}$, com maior aporte foliar sincronizado à fração reprodutiva e estação chuvosa, conforme é demonstrado na figura 3 .

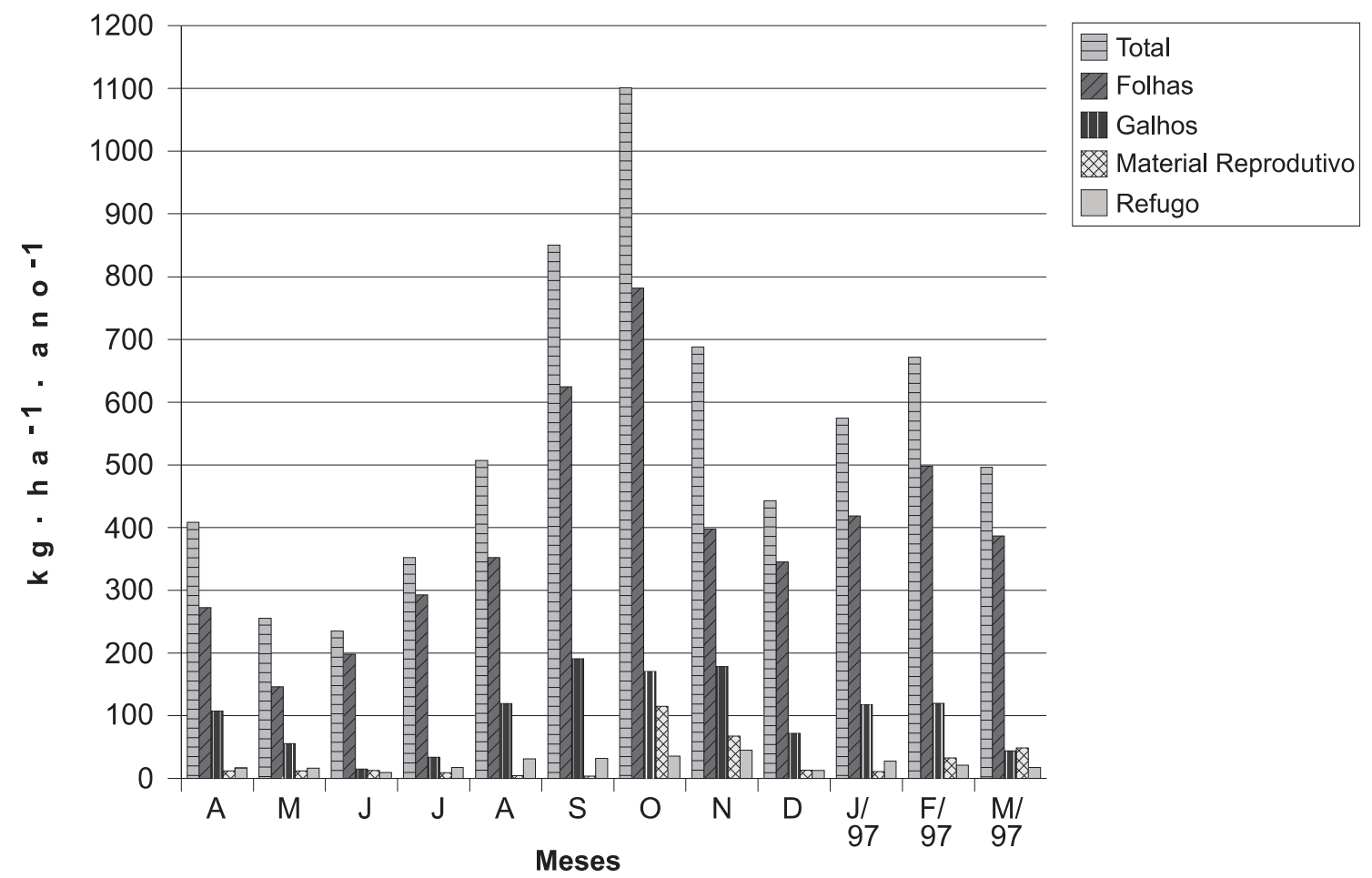

Figura 3 - Aporte de serrapilheira em $\mathrm{kg} \mathrm{ha}^{-1} \mathrm{mês}^{-1}$ entre as diferentes frações em floresta de baixada (40 anos) na REBIO de Poço das Antas durante abril de 1996 a março de 1997. 
As contribuições em \% e biomassa para as diferentes frações do folhedo na floresta intermediária foram: $66,5 \%\left(3.645,0 \mathrm{~kg} \mathrm{ha}^{-1}\right.$ ano $\left.^{-1}\right)$ para a fração foliar, $18 \%(987,2 \mathrm{~kg}$ $\left.\mathrm{ha}^{-1} \mathrm{ano}^{-1}\right)$ galhos, 11,6\% (634,3 $\left.\mathrm{kg} \mathrm{ha}^{-1} \mathrm{ano}^{-1}\right)$ material reprodutivo, $3,9 \%\left(212,7 \mathrm{~kg} \mathrm{ha}^{-1} \mathrm{ano}^{-1}\right)$ refugo e com o aportado total de $5.479,2 \mathrm{~kg}$ ha${ }^{1}$ ano $^{-1}$. A maior contribuição foliar antecedeu a maior contribuição da fração reprodutiva e após o período de seca (Fig. 4).

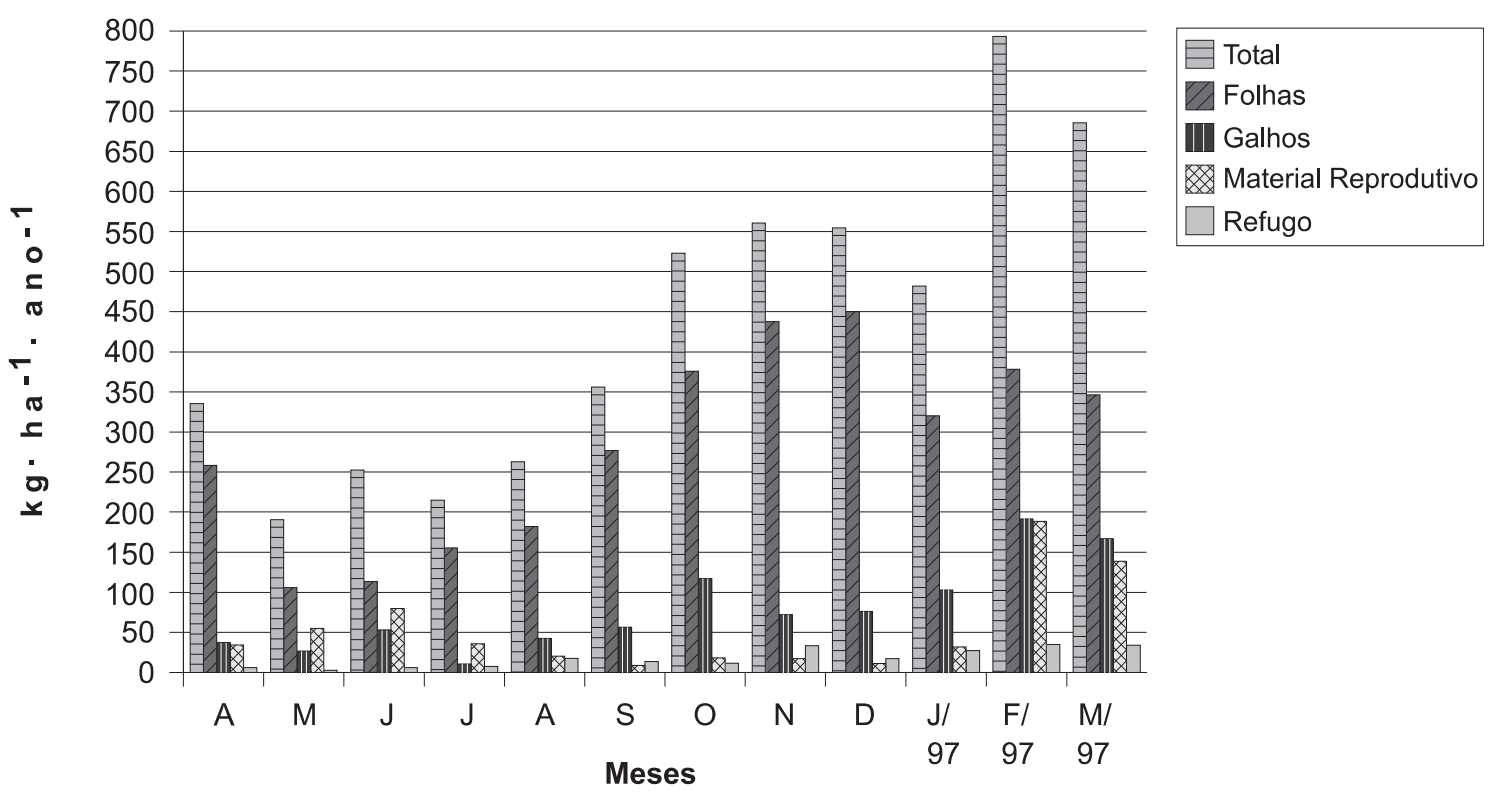

Figura 4 - Aporte de serrapilheira em kg ha-1 mês $^{-1}$ entre as diferentes frações em Floresta de Baixada (20 anos) na REBIO de Poço das Antas durante abril de 1996 a março de 1997.

As contribuições em \% e biomassa em reflorestamento de Mimosa bimucronata às frações obtiveram: $72,5 \%$ $\left(2.192,4 \mathrm{~kg} \mathrm{ha}^{-1} \mathrm{ano}^{-1}\right)$ para a fração foliar, $16,7 \%\left(504,4 \mathrm{~kg} \mathrm{ha}^{-1} \mathrm{ano}^{-1}\right)$ galhos, 2,7\% $\left(81,7 \mathrm{~kg} \mathrm{ha}^{-1} \mathrm{ano}^{-1}\right)$ material reprodutivo e $8,2 \%\left(247,0 \mathrm{~kg} \mathrm{ha}^{-1} \mathrm{ano}^{-1}\right)$ para folhas de outras espécies associadas ao plantio de Mimosa bimucronata; o total aportado foi de $3.025,5 \mathrm{~kg} \mathrm{ha}^{-1}$ ano $^{-1}$, com fenologia do aporte similar à floresta avançada, onde o maior aporte está sincronizado à estação reprodutiva e chuvosa (Fig. 5).

A produtividade em diferentes regiões do globo foi até o presente, vastamente estudada e enfocada por diversos autores, mas muito pouco levando-se em conta os diferentes estágios sucessionais em uma mesma fitofisionomia.

Em todos os estágios estudados a contribuição da fração foliar encontrada na serrapilheira anual, demonstrou proporções próximas a $70 \%$ do total aportado. O mesmo foi encontrado em outras florestas tropicais por (Andrade 1997; Brina et al. 1998; Dias 1997; Klinge \& Rodrigues 1968; Linera \& Tolome 1996; Mello \& Porto 1994; Morellato 1987; O’Neill \& De Angelis 1980; Prazeres et al. 1998; Sanchez \& Sada 1993; Veneklaas 1991, entre muitos outros). 
Quando analisadas correlações de precipitação e temperatura com o valor aportado sobre o solo às diferentes frações, bem como o total de serrapilheira; os resultados demonstram que os sistemas em expansão respondem mais a precipitação quando comparados ao sistema avançado, enquanto este último, é mais influenciado pela temperatura (Tabela 3).

Tabela 3 - Correlações de precipitação e temperatura média às diferentes frações e total de serrapilheira aportada ao solo.

\begin{tabular}{|c|c|c|c|c|c|}
\hline \multicolumn{6}{|c|}{ Correlações para a Floresta Avançada (40anos) } \\
\hline \multicolumn{6}{|c|}{ Precipitação mensal } \\
\hline Aporte mensal & Total & Folhas & Galhos & Material Reprodutivo & Refugo \\
\hline Correlação & 0,17 & 0,09 & 0,33 & 0,07 & 0,33 \\
\hline \multicolumn{6}{|c|}{ Temperatura média } \\
\hline Correlação & 0,22 & 0,21 & 0,2 & 0,27 & 0,08 \\
\hline \multicolumn{6}{|c|}{ Correlações para a Floresta Intermediária (20anos) } \\
\hline \multicolumn{6}{|c|}{ Precipitação mensal } \\
\hline Aporte mensal & Total & Folhas & Galhos & Material Reprodutivo & Refugo \\
\hline Correlação & 0,48 & 0,59 & 0,78 & 0,55 & 0,56 \\
\hline $\begin{array}{l}\text { Coef. Det. \% } \\
\text { Regressão y = }\end{array}$ & $\begin{array}{c}61 \\
234,35+1,07 x\end{array}$ & $\begin{array}{c}35 \\
189,08+0,51 x\end{array}$ & $\begin{array}{c}62 \\
22,22+0,31 x\end{array}$ & & \\
\hline \multicolumn{6}{|c|}{ Temperatura média } \\
\hline Correlação & 0,43 & 0,3 & 0,38 & 0,42 & 0,27 \\
\hline \multicolumn{6}{|c|}{ Correlações para o Campo Antrópico - Plantio (3 anos) } \\
\hline \multicolumn{6}{|c|}{ Precipitação mensal } \\
\hline Aporte mensal & Total & Folhas & Galhos & Material Reprodutivo & Refugo \\
\hline Correlação & 0,52 & 0,49 & 0,26 & 0,7 & 0,62 \\
\hline $\begin{array}{l}\text { Coef. Det. \% } \\
\text { Regressão y = }\end{array}$ & & & & $\begin{array}{c}49 \\
-4,89+0,06 x\end{array}$ & $\begin{array}{c}38 \\
-4,41+0,13 x\end{array}$ \\
\hline \multicolumn{6}{|c|}{ Temperatura média } \\
\hline Correlação & 0,25 & 0,26 & 0 & 0,51 & 0,25 \\
\hline
\end{tabular}

A partir da interpretação concomitante dos dados climáticos e da produtividade de serrapilheira em áreas de baixada na REBIO de Poço das Antas, é proposto o conceito de que a maior queda das folhas ocorre regulada pela menor oferta de água para a vegetação. Ou seja, como é na estação inverno (entre os meses de maio a agosto) que o índice pluviométrico é o menor quando comparado as demais estações do ano, a vegetação uma vez exposta a períodos secos prolongados, por necessitar de um recurso que se torna escasso, acaba por permitir a abcisão foliar, representando assim uma estratégia para minimizar a menor disponibilidade de água, já que com menos folhas a necessidade de água para a vegetação acaba por ser menor.

Sanchez \& Sada (1993) estudando a Floresta Tropical localizada em áreas de baixada no México encontraram a maior queda das folhas sincronizada ao período de menor pluviosidade para a estação outono. Já na 
Floresta da Tijuca, RJ - Brasil, (Oliveira et. al. 1993) ao estudarem a queda de folhas, identificaram dois picos de produção de serrapilheira como sendo os meses de junho e julho na estação inverno e dezembro e fevereiro na estação verão, ambos como o período sincronizado a menor taxa pluviométrica. Dias (1997), encontrou na Floresta Estacional
Semidecídua Montana localizada em Lavras, MG - Brasil, a maior produtividade de serrapilheira à estação primavera, enquanto Leitão-Filho (1993), ao estudar a Mata Atlântica de Cubatão, SP - Brasil, determinou como período, o verão; períodos estes também sincronizados aos meses de menor pluviosidade nas regiões estudadas.

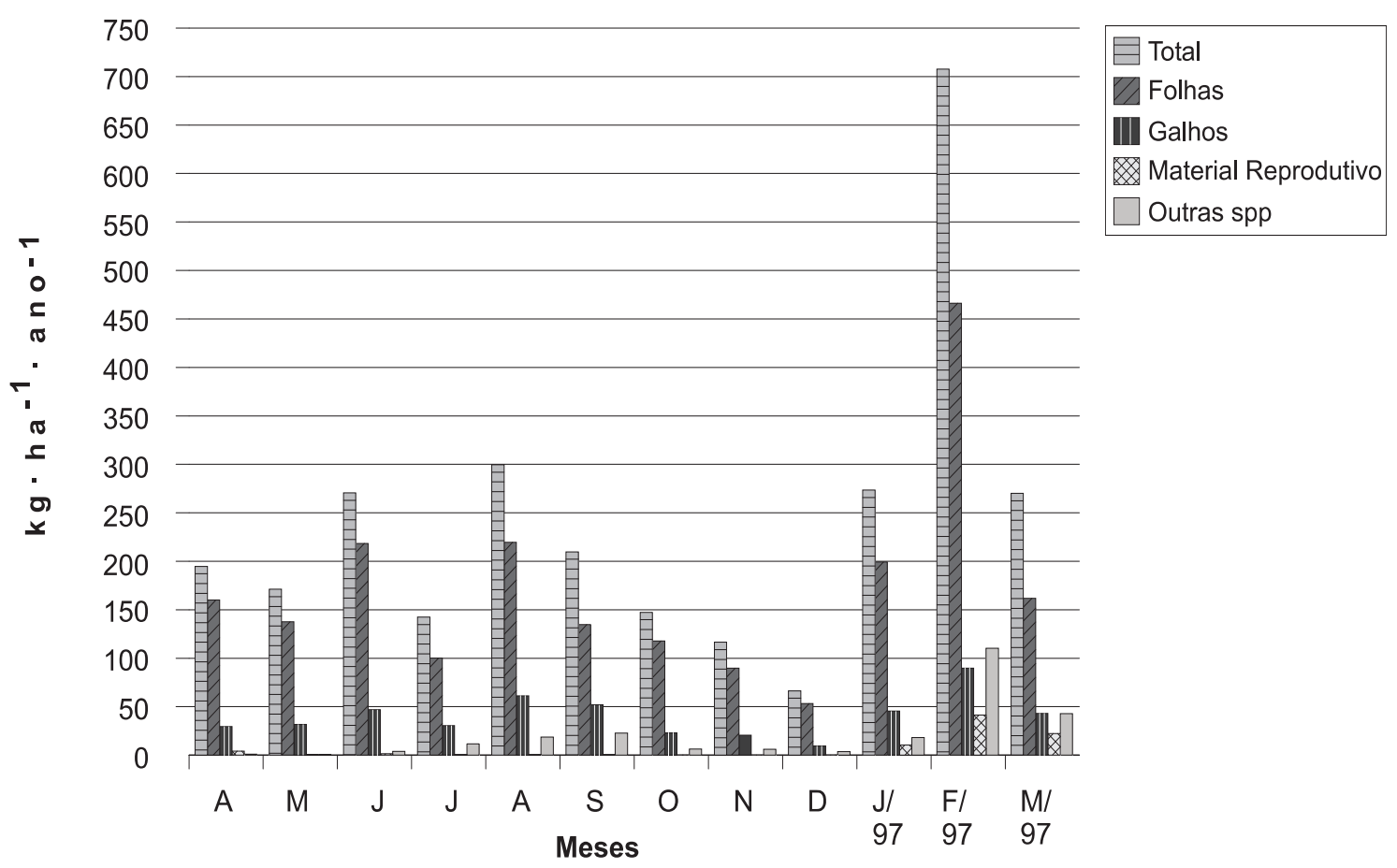

Figura 5 - Aporte de serrapilheira em kg ha ${ }^{-1} \mathrm{mês}^{-1}$ entre as diferentes frações em Campo Antrópico (3 anos), na REBIO de Poço das Antas durante abril de 1996 a março de 1997.

\section{Teor de nutrientes da serrapilheira}

Foram detectadas para o plantio maiores concentrações médias anuais em $\mathrm{g} \mathrm{kg}^{-1}$ de $\mathrm{N}$ $(14,95 \pm 0,95), \mathrm{P}(0,9 \pm 0,1), \mathrm{K}(5,5 \pm 0,5) \mathrm{e}$ $\mathrm{Ca}(21,0 \pm 6,7)$, e maiores na estação chuvosa. Já o Mg apresentou maiores concentrações em valores absolutos à floresta avançada na estação seca $(2,5 \pm 0,2)$. A magnitude da transferência dos nutrientes encontrados na fração foliar aos estágios florestais, seguiu a relação de concentração: $\mathrm{P}<\mathrm{K}<\mathrm{Mg}<\mathrm{Ca}<\mathrm{N}<\mathrm{C}$, (Tabela 4).

As concentrações de $\mathrm{C}, \mathrm{N}, \mathrm{P}, \mathrm{K}$ e $\mathrm{Mg}$ não demonstraram diferenças significativas a todos os estágios entre as estações. Sendo o Ca diferente apenas no plantio (maior na chuvosa), devido a elevada variação dos valores encontrados nas repetições. O P apresentou a menor concentração entre todos os nutrientes averiguados. 
Tabela 4 - Comparações dos nutrientes estudados na serrapilheira (fração foliar) entre os estágios e dentro às diferentes estações.

\begin{tabular}{|c|c|c|c|c|c|c|}
\hline \multicolumn{7}{|c|}{ CONCENTRAÇÃO FOLIAR em g. $\mathrm{kg}^{-1}$} \\
\hline \multirow[t]{3}{*}{ SISTEMA } & \multirow{2}{*}{$\begin{array}{l}\text { IDADE } \\
\text { ANOS }\end{array}$} & \multirow[b]{2}{*}{ Média Anual \pm Erro Padrão } & \multirow[b]{2}{*}{$\mathrm{CV} \%$} & \multicolumn{3}{|c|}{ ESTAÇÕES } \\
\hline & & & & SECA & & CHUVOSA \\
\hline & \multicolumn{6}{|c|}{ Carbono } \\
\hline Floresta Avançada & 40 & $497,62 \pm 5,53$ a & 2,2 & $\mathbf{4 9 0 , 5} \pm 9,0$ & NS & $\mathbf{5 0 4 , 7} \pm 3,6$ \\
\hline Floresta Intermediária & 20 & $497,92 \pm 4,75$ a & 1,9 & $499,8 \pm 3,4$ & NS & $\mathbf{4 9 6 , 1} \pm 29,5$ \\
\hline \multirow[t]{2}{*}{ Reflorestamento } & 3 & $\mathbf{5 0 1 , 1 3} \pm 7,99$ a & 3,2 & $\mathbf{5 1 2 , 6} \pm 6,2$ & NS & $\mathbf{4 8 9}, 7 \pm 20,9$ \\
\hline & \multicolumn{6}{|c|}{ Nitrogênio } \\
\hline Floresta Avançada & 40 & $\mathbf{1 0 , 3 0} \pm 0,39 \mathbf{b}$ & 7,8 & $\mathbf{1 0 , 1} \pm 0,6$ & NS & $\mathbf{1 0 , 0} \pm 1,7$ \\
\hline Floresta Intermediária & 20 & $\mathbf{1 0 , 6 7} \pm 0,72 \mathbf{b}$ & 13,5 & $\mathbf{1 0 , 7} \pm 2,1$ & NS & $\mathbf{1 0 , 7} \pm 0,4$ \\
\hline \multirow[t]{2}{*}{ Reflorestamento } & 3 & $\mathbf{1 4 , 9 5} \pm 0,95 \mathbf{a}$ & 12,7 & $\mathbf{1 4 , 1} \pm 2,8$ & NS & $15,8 \pm 3,9$ \\
\hline & \multicolumn{6}{|c|}{$\mathrm{C} / \mathrm{N}$} \\
\hline Floresta Avançada & 40 & $\mathbf{5 0 , 0 0} \pm 2,00 \quad \mathbf{a}$ & 8,0 & $49,0 \pm 3,0$ & NS & $\mathbf{5 1 , 0} \pm 8,0$ \\
\hline Floresta Intermediária & 20 & $47,00 \pm 3,00 \quad \mathbf{a}$ & 13,5 & $47,0 \pm 9,0$ & NS & $\mathbf{4 6 , 0} \pm 4,0$ \\
\hline \multirow[t]{2}{*}{ Reflorestamento } & 3 & $\mathbf{3 4 , 0 0} \pm 2,00 \quad \mathbf{b}$ & 13,4 & $\mathbf{3 7 , 0} \pm 7,0$ & NS & $\mathbf{3 1 , 0} \pm 7,0$ \\
\hline & \multicolumn{6}{|c|}{$\mathbf{P}$} \\
\hline Floresta Avançada & 40 & $\mathbf{0 , 5 0} \pm \quad 0 \quad \mathbf{b}$ & 10,0 & $\mathbf{0 , 5} \pm 0$ & NS & $\mathbf{0 , 5} \pm 0,2$ \\
\hline Floresta Intermediária & 20 & $\mathbf{0 , 4 0} \pm 0,10 \quad \mathbf{b}$ & 40,0 & $\mathbf{0 , 5} \pm 0,1$ & NS & $\mathbf{0 , 3} \pm 0,4$ \\
\hline \multirow[t]{2}{*}{ Reflorestamento } & 3 & $\mathbf{0 , 9 0} \pm 0,10 \quad \mathbf{a}$ & 25,7 & $\mathbf{0 , 8} \pm 0,4$ & NS & $\mathbf{1 , 0} \pm 0,6$ \\
\hline & \multicolumn{6}{|c|}{$\mathbf{K}$} \\
\hline Floresta Avançada & 40 & $\mathbf{2 , 4 2} \pm 0,32 \quad \mathbf{b}$ & 26,3 & $2,7 \pm 1,1$ & NS & $\mathbf{2 , 2} \pm 0,4$ \\
\hline Floresta Intermediária & 20 & $\mathbf{1 , 8 9} \pm 0,36 \mathbf{b}$ & 38,6 & $2,2 \pm 1,8$ & NS & $\mathbf{1 , 6} \pm 0,4$ \\
\hline \multirow[t]{2}{*}{ Reflorestamento } & 3 & $\mathbf{5 , 4 6} \pm 0,51$ a & 18,8 & $2,5 \pm 1,7$ & NS & $\mathbf{5 , 7} \pm 1,7$ \\
\hline & \multicolumn{6}{|c|}{$\mathrm{Ca}$} \\
\hline Floresta Avançada & 40 & $\mathbf{8 , 3 0} \pm 1,20 \mathbf{b}$ & 29,1 & $\mathbf{8 , 3} \pm 1,2$ & NS & $\mathbf{8 , 3} \pm 1,1$ \\
\hline Floresta Intermediária & 20 & $\mathbf{6 , 6 1} \pm 0,84 \quad \mathbf{b}$ & 25,4 & $\mathbf{6 , 6} \pm 2,0$ & NS & $\mathbf{6 , 7} \pm 1,3$ \\
\hline \multirow[t]{2}{*}{ Reflorestamento } & 3 & $\mathbf{2 1 , 0 3} \pm 6,66 \mathbf{a}$ & 28,2 & $\mathbf{2 0 , 4} \pm 4,6$ & $\mathrm{~S}$ & $\mathbf{2 1 , 6} \pm 24,3$ \\
\hline & \multicolumn{6}{|c|}{ Mg } \\
\hline Floresta Avançada & 40 & $\mathbf{2 , 5 0} \pm 0,20 \quad \mathbf{a}$ & 17,8 & $2,7 \pm 0,3$ & NS & $2,4 \pm 0,6$ \\
\hline Floresta Intermediária & 20 & $\mathbf{2 , 3 0} \pm 0,10 \quad \mathbf{a}$ & 8,4 & $\mathbf{2 , 3} \pm 0,5$ & NS & $2,4 \pm 0,5$ \\
\hline Reflorestamento & 3 & $\mathbf{2 , 2 0} \pm 0,10$ a & 6,3 & $\mathbf{2 , 2} \pm 0,4$ & NS & $\mathbf{2 , 2} \pm 0,1$ \\
\hline
\end{tabular}

Estimativa da média \pm seu erro padrão ( $\mathrm{t}$ - Student com $\mathrm{p} \leq 0,05), \mathrm{n}=9$ (estações) e 18 (anual), teste Tukey a $5 \%$ de significância entre os estágios, letras diferentes indicam diferença. 
Concentrações anuais dos nutrientes retornados ao solo

As concentrações anuais encontradas para o $\mathrm{N}$ em ambos os estágios florestais, foram maiores que a encontrada no plantio com $\left(32,9 \pm 7,6 \mathrm{~kg} \mathrm{ha}^{-1} \mathrm{ano}^{-1}\right)$, sendo o $\mathrm{N}$, com exceção do $\mathrm{C}$, o nutriente de maior aporte ao solo via fração foliar quando comparado aos demais nutrientes, seguido logo após pelo $\mathrm{Ca}$. O plantio apresentou maiores aportes anuais em $\mathrm{P}, \mathrm{K}$ e $\mathrm{Ca}$ quando comparado a floresta intermediária.

Os totais aportados de C, N e Mg são maiores nos estágios florestais quando comparados ao plantio. Menor deposição de
$\mathrm{K}$ na floresta intermediária entre todos os estágios, e maiores na floresta avançada para N, P, Ca e Mg, (Tabela 5).

Anualmente, são depositados via serrapilheira na floresta de baixada avançada, cerca de 49,8 $\mathrm{kg} \mathrm{ha}^{-1}$ de $\mathrm{N}, 41,3$ $\mathrm{kg} \mathrm{ha}^{-1}$ de Ca, 12,0 $\mathrm{kg} \mathrm{ha}^{-1}$ de K, 12,5 kg $\mathrm{ha}^{-1}$ de $\mathrm{Mg}$ e 2,4 $\mathrm{kg} \mathrm{ha}^{-1}$ de P. Para a floresta em estágio intermediário foram encontrados $39,0 \mathrm{~kg} \mathrm{ha}^{-1}$ de N, 24,1 $\mathrm{kg} \mathrm{ha}^{-1}$ de Ca, 6,9 $\mathrm{kg} \mathrm{ha}^{-1}$ de K, 8,4 $\mathrm{kg} \mathrm{ha}^{-1}$ de $\mathrm{Mg}$ e 1,4 $\mathrm{kg} \mathrm{ha}^{-}$ 1 de P. Já para o plantio de Mimosa bimucronata, $32,9 \mathrm{~kg} \mathrm{ha}^{-1}$ de $\mathrm{N}, 38,1 \mathrm{~kg}$ $\mathrm{ha}^{-1}$ de Ca, 12,1 $\mathrm{kg} \mathrm{ha}^{-1}$ de K, 4,8 $\mathrm{kg} \mathrm{ha}^{-1}$ de $\mathrm{Mg}$ e $1,9 \mathrm{~kg} \mathrm{ha}^{-1}$ de $\mathrm{P}$.

Tabela 5: Aporte ao solo via serrapilheira (fração foliar) em kg ha ${ }^{-1} \mathrm{ano}^{-1} \mathrm{em}$ diferentes estágios sucessionais encontrados na REBIO de Poço das Antas.

\begin{tabular}{|c|c|c|c|c|c|c|c|}
\hline & APORTE AO & SOLO VI & A FRAÇ & Ĩo FOLIA & R EM $k$ & $\mathrm{ha}^{-1} \mathrm{ano}^{-1}$ & \\
\hline ÁREA & C & $\mathbf{N}$ & $\mathbf{P}$ & $\mathbf{K}$ & $\mathrm{Ca}$ & Mg & $\begin{array}{l}(\mathbf{N}+\mathbf{P}+\mathbf{K} \\
+\mathbf{C a}+\mathbf{M g})\end{array}$ \\
\hline $\begin{array}{c}\text { FLORESTA } \\
\text { (40 anos) }\end{array}$ & $\mathbf{2 . 4 7 8 , 0 + - 3 0 8 , 3}$ & $49,8+-6,2$ & $\mathbf{2 , 4 + - 0 , 3}$ & $\mathbf{1 2 , 0}+-1,5$ & $41,3+-5,1$ & $\mathbf{1 2 , 5 + - 1 , 5}$ & 118 \\
\hline $\begin{array}{l}\text { FLORESTA } \\
\text { (20 anos) }\end{array}$ & $\mathbf{1 . 8 1 4 , 8 + - ~} 183,6$ & $\mathbf{3 9 , 0 + - 3 , 9}$ & $1,4+-0,1$ & $\mathbf{6 , 9 + - ~ 0 , 7}$ & $\mathbf{2 4 , 1 + - 2 , 4}$ & $\mathbf{8 , 4}+-0,8$ & 80 \\
\hline $\begin{array}{l}\text { PLANTIO } \\
\text { (3 anos) }\end{array}$ & $\mathbf{1 . 0 9 8 , 6 + -} 254,3$ & $32,9+-7,6$ & $\mathbf{1 , 9 + - ~} 0,4$ & $\mathbf{1 2 , 1}+-2,8$ & $\mathbf{3 8 , 1}+-8,8$ & $4,8+-1,1$ & 90 \\
\hline
\end{tabular}

Médias a partir de 18 repetições e erro-padrão ( $\mathrm{t}$ - Student) com $\mathrm{p} \leq 0,05$.

Quando comparadas as porcentagens entre os diferentes nutrientes averiguados na deposição foliar da serrapilheira para cada um dos estágios estudados, conforme apresentado nas Figura 6, verificou-se que: o $\mathrm{N}$ apresenta maior retorno na floresta intermediária com $48 \%$. O P com $2 \%$ em todos os estágios, demonstrando ser o nutriente mais limitante. $\mathrm{K}$ e Ca, 13 e $43 \%$ respectivamente, ambos maiores no plantio, enquanto o $\mathrm{Mg}$ com $11 \%$ em ambos os estágios florestais. Acredita-se a partir destes resultados que o plantio apresenta a menor eficiência quanto a absorção foliar dos nutrientes, caracterizandose como o sistema mais "aberto" quanto a ciclagem de nutrientes quando comparado aos demais estágios. E que entre os estágios florestais, a floresta intermediária é a mais eficiente, demonstrando ser este o sistema mais "fechado". 


\section{Floresta Avançada}

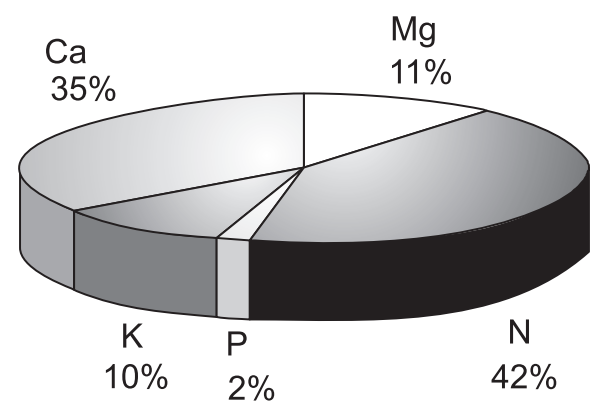

\section{Floresta Intermediária}

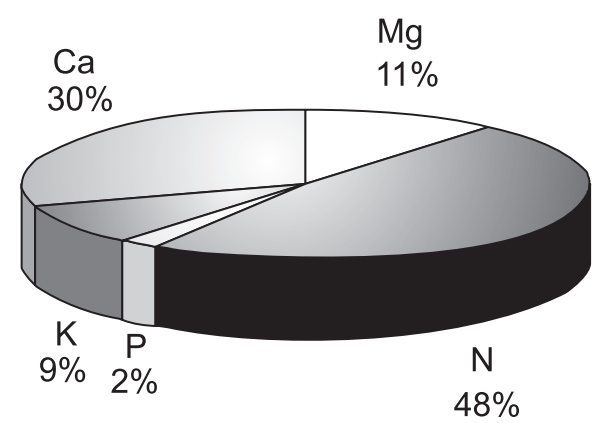

\section{Campo Antrópico - Plantio}

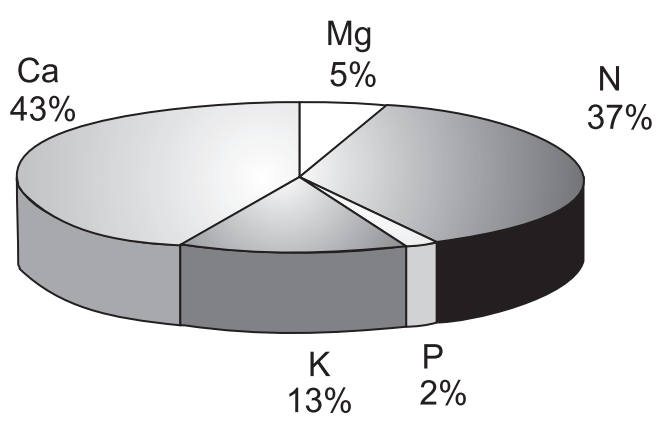

Figuras 6 - Porcentagens de retorno ao solo para os nutrientes averiguados na fração foliar para as florestas avançada, intermediária e campo antrópico.

\section{Eficiência na utilização dos nutrientes}

Neste estudo somente a concentração de $\mathrm{Mg}$ não foi verificada maior em Mimosa bimucronata quando comparada a encontrada nos estágios florestais. A concentração deste nutriente está relacionada aos pigmentos clorofilados, conotando uma maior produtividade primária em sistemas iniciais. Entretanto isto não foi verificado, o que pode estar relacionado a uma maior concentração deste elemento nas folhas dos estágios florestais, uma vez que a análise química se reportou a mistura de folhas de diferentes espécies, aumentando seu conteúdo nutricional quando comparado especificamente ao encontrado em Mimosa bimucronata, em valores absolutos; já quando comparada a concentração média entre os diferentes estágios, não foi verificada diferença significativa.

É de se esperar que estágios florestais secundários apresentam menores fluxos quanto às concentrações de entrada de nutrientes; a partir de uma maior eficiência econômica. Uma vez que através de uma maior biomassa epígea conseguem retranslocar e armazenar maiores concentrações entre os diferentes nutrientes antes da abscissão foliar (Vitousek 1984).

Os índices de eficiênica no retorno de nutrientes ao solo são apresentados como a relação entre a quantidade de serrapilheira produzida e a quantidade de nutrientes nela contida, (Moraes 1993). Quando o índice apresenta-se menor, indica uma menor eficiência econômica na utilização desses nutrientes pela comunidade vegetal.

$\mathrm{O}$ maior índice de eficiência para o $\mathrm{N}$ (100), foi encontrado na floresta avançada, seguido pela floresta intermediária com 93 e por último o plantio com 67, enquanto ao analisarmos $\mathrm{N}+\mathrm{P}+\mathrm{K}+\mathrm{Ca}+\mathrm{Mg}$, o melhor índice é apresentado pela floresta intermediária com 46, seguido pela floresta avançada com 42 e o plantio com 24.

$\mathrm{Na}$ estação chuvosa, o estágio intermediário encontra-se encharcado, o que acaba por contribuir para o aumento da 
dissolução e da concentração de nutrientes em seu solo de caráter oligotrófico. E a partir de um maior esforço reprodutivo, determina assim uma estratégia em alocar nutrientes na própria biomassa vegetal quando se prepara para um aumento de sua biomassa favorecido também pelo baixo potencial de exportação de nutrientes. Desta forma é explicado seu maior índice de eficiência nutricional, conforme é demonstrado na tabela 6 .

Tabela 6 - Índice de eficiência na serrapilheira (fração foliar) entre os estágios florestais para os nutrientes averiguados.

\begin{tabular}{|c|c|c|c|c|c|c|c|}
\hline \multicolumn{8}{|c|}{$\begin{array}{c}\text { Índice de Eficiência na Serrapilheira - Fração Foliar } \\
\text { (ton. } \mathrm{ha}^{-1} \text { ano }^{-1} \text { de Serrapilheira } / \mathrm{kg} \mathrm{ha}^{-1} \text { ano }^{-1} \text { de Nutrientes) }\end{array}$} \\
\hline \multicolumn{8}{|l|}{ Área } \\
\hline & C & $\mathbf{N}$ & $\mathbf{P}$ & $\mathbf{K}$ & $\mathrm{Ca}$ & Mg & Exceto $\mathrm{C}$ \\
\hline Floresta Avançada & 2 & 100 & 2075 & 415 & 121 & 398 & 42 \\
\hline Floresta Intermediária & 2 & 93 & 2604 & 528 & 151 & 434 & 46 \\
\hline Plantio & 2 & 67 & 1154 & 181 & 58 & 457 & 24 \\
\hline
\end{tabular}

\section{Conclusões}

De acordo com os resultados observados conclui-se que:

A estratégia da renovação foliar ocorre sob o ritmo perenifólio, seu aporte ao solo se dá de forma ininterrupta aos estágios de baixada estudados, sendo maiores na estação chuvosa e sincronizado a fase reprodutiva para a espécie Mimosa bimucronata.

Quando o fenômeno da falta d' água expõe a vegetação a um possível estresse hídrico, caracteriza-se o evento mais responsável e influenciador da queda de folhas nas florestas tropicais.

A floresta avançada apresentou o maior aporte total, 6,9 $\pm 1,1$ ton ha ${ }^{-1}$ ano ${ }^{-1}$, quando comparada ao estágio intermediário com 5,5 $\pm 0,5$ ton ha ${ }^{-1}$ ano ${ }^{-1}$ e $3,0 \pm 0,7$ ton ha ${ }^{-1}$ ano

${ }^{1}$ para o plantio.

A fração folhas obteve um maior aporte, seguida das frações galhos, material reprodutivo e refugo respectivamente $\mathrm{em} \mathrm{kg}$ ha $^{-1}$ ano $^{-1}$ em todos os estágios.

Não foi encontrada diferença significativa à composição nutricional na fração foliar da serrapilheira entre as estações a todos os estágios.

As concentrações totais anuais médias de entrada dos nutrientes $\mathrm{C}, \mathrm{N}$ e $\mathrm{Mg}$ em florestas avançada e intermediária são ambas maiores que as encontradas no plantio, enquanto para $\mathrm{P}, \mathrm{K}$ e $\mathrm{Ca}\left(\mathrm{em} \mathrm{kg} \mathrm{ha}{ }^{-1} \mathrm{ano}^{-1}\right)$ foram encontradas menores na floresta intermediária.

A magnitude de transferência aos estágios intermediário e avançado segue a ordem de concentração: $\mathrm{P}<\mathrm{K}<\mathrm{Mg}<\mathrm{Ca}<$ $\mathrm{N}<\mathrm{C}$, enquanto para o plantio, $\mathrm{K}>\mathrm{Mg}$.

As concentrações de entrada dos nutrientes: $\mathrm{C}, \mathrm{N}, \mathrm{P}, \mathrm{K}$ e $\mathrm{Ca}$ em $\mathrm{g} \mathrm{kg}^{-1} \mathrm{de}$ serrapilheira (fração foliar) no estágio inicial com o uso de Mimosa bimucronata demonstraram-se elevadas, e esta planta como uma espécie favorável a recomposição de áreas degradadas, caracterizando-se como de potencial elevado às taxas utilizadas na expansão de sistemas. Em virtude de sua relação $\mathrm{C} / \mathrm{N}$, seu conteúdo nutricional, através da decomposição é liberado de forma mais lenta. 
Comparações do aporte total e foliar demonstraram a floresta avançada com o maior índice de eficiência de nutrientes para o nitrogênio. Enquanto que a floresta intermediária provavelmente através de sua estratégia reprodutiva, aloca os nutrientes na biomassa e minimiza "as perdas" através de seu alto índice de eficiência na exportação dos demais nutrientes via serrapilheira.

\section{Agradecimentos}

Agradecemos a CAPES pela concessão da bolsa de mestrado; a EMBRAPA por disponibilizar suas dependências para moagem e análises químicas do material, ao Instituto de Pesquisas Jardim Botânico do Rio de Janeiro em especial à pesquisadora Tânia Sampaio por disponibilizar o Laboratório de Sementes para triagem, secagem e pesagem do material, ao IBAMA por autorizar as coletas na REBIO de Poço das Antas - RJ e aos senhores Fortunato F. Barbosa, Joaquina de S. C. Barbosa e Fabiano C. Barbosa pelo incentivo na condução deste trabalho.

\section{REFERÊNCIAS BIBLIOGRÁFICAS}

Andrade, A. G. 1997. Ciclagem de nutrientes e arquitetura radicular de leguminosas arbóreas de interesse para revegetação de solos degradados e estabilização de encostas. Tese de Doutorado. Universidade Federal Rural do Rio de Janeiro, Seropédica, 165p.

Baillie, I. C. 1989. Soil characteristics and mineral nutrition of tropical wooded ecosystems. In: Proctor, J. (ed). Mineral nutrients in tropical forest and savanna ecosystems. Blackwell Scientific Publications, Oxford. Pp. 15-26.

Bataglia, O. C.; Furlani, A. M. C.; Teixeira, J. P. F.; Furlani, P. R.; Gallo, J. R. 1983. Métodos de análise química de plantas. Boletim Técnico, 78. IAC, Campinas, 48p.

Bremmer, J. M. 1965. Total nitrogen. In: Black, C. A.; Evans, D. D.; White, J. L.; Ensminger, L. E. \& F. E. Clark (eds.).
Methods of soil analysis. American Society of Agronomy, Inc., Madison. Pp. 1149-1237.

Brina, A. E. \& Filho, J. P. L. 1998. Produção e conteúdo de nutrientes na serrapilheira em mata mesófila associada a afloramentos calcários em Minas Gerais, Brasil. In: Congresso Nacional de Botânica, XLIX. Anais, Salvador. Pp. 310-311.

Bruijnzeel, L. A. 1991. Nutrient input-output budgets of tropical forest ecosystems: a review. Journal of Tropical Ecology 7: 1-24.

Dias, H. C. T. 1997. Fenologia de quatro espécies arbóreas e variação temporal e espacial da produção de serapilheira em uma floresta estacional semidecídua montana em Lavras - MG. Revista Árvore, 21(1): 1-50.

Empresa Brasileira de Pesquisa Agropecuária. 1979. Serviço Nacional de Levantamento e Conservação de Solos. Rio de Janeiro. Manual de métodos de análises de solo. RJ. SNLCS, v.1.

Facelli, J. M. \& Pickett, S. T. A. 1991. Plant litter: its dynamics and effects on plant community structure. The Botanical Review, 57(1): 1-32.

Franco, A. A. \& Campello, E. F. C. 1997. Importância da qualidade da serrapilhiera na sucessão vegetal em áreas de recuperação na Amazônia. In: Encontro brasileiro sobre substâncias húmicas, II. São Carlos - SP. Anais. Editores Nadislau Martin Neto, Carlos Clemente Cerri e Wanderley J. De Melo. Empresa brasileira de Pesquisa Agropecuária. Centro Nacional de Pesquisa e Desenvolvimento de Instrumentação Agropecuária. São Carlos: EMBRAPA - CNPDIA, 208p.

Herrera, R.; Jordan, D. F.; Klinge, H. \& Medina, E. 1978. Amazon ecosystems: their stuctrure and functioning with particular emphasis on nutrients. Interciência 3: 223-232. 
Hungria, M. \& Araújo, R. S. 1994. Manual de métodos empregados em estudos de microbiologia agrícola; EMBRAPA, Centro Nacional de Pesquisa de Arroz e Feijão, CNP de Soja. EMBRAPASPI, Brasília, 542p.

Instituto Brasileiro de Desenvolvimento Florestal. 1981. Plano de manejo da Reserva Biológica de Poço das Antas. Doc. Téc. nº 10. IBDF, Brasília, 94p.

Jones Jr., J. B. 1991. Kjeldahl method for nitrogen determination. Micro-macro publishings, Athens, GA, 78p.

Klinge, H. \& Rodrigues, W. 1968. Litter production in an area of Amazonian terra firme forest. I. Litterfall, organic carbon and total nitrogen contents of litter. Amazoniana 1: 303-310.

Koeppen, W. 1948. Climatologia; versão para o espanhol de Pedro R. Hendrichs Pérez. México, Fondo de Cultura Econômica, 469p.

Leitão-Filho, H. F. 1993. Ecologia da Mata Atlântica em Cubatão (SP). Editora Univ. Est. Paulista, Campinas (Natura Naturata). Pp.144-163.

Linera, G. W. \& Tolome, J. 1996. Litterfall, temperate and tropical dominant trees, and climate in a mexican lower montane forest. Biotropica 28(4b): 649-656.

Mello, R. S. P. \& Porto, M. L. 1994. Produção de serrapilheira em comunidades florestais do Morro do Pinhal, Parobé, RS. In: Congresso Nacional de Botânica, XLV. Anais, São Leopoldo. P. 40.

Moraes, R. M. 1993. Ciclagem de nutrientes minerais em Mata Atlântica de Encosta e mata sobre Restinga, na Ilha do Cardoso, Cananéia, SP: Produção de serapilheira e transferência de nutrientes. Dissertação de Mestrado. Universidade de São Paulo, São Paulo, 151p.

Morellato-Fonzar, L. P. C. 1987. Estudo comparativo de fenologia e dinâmica de duas formações florestais na Serra do
Japi, Jundiaí, SP. Dissertação de Mestrado. Universidade de São Paulo, São Paulo, 232p.

Myers, R. J. K.; Palm, C. A.; Cuevas, E.; Gunatilleke, I. U. N. \& Brossard, M. 1994. The synchronisation of nutrient mineralisation and plant nutrient demand. The biological Management of Tropical Soil Fertility. P. L. Woomer \& M. J. Swift,. Pp. 81-116.

Oliveira, R. R. \& Lacerda, L. D. 1993. Produção e composição química da serrapilheira na Floresta da Tijuca (RJ). Revista Brasileira de Botânica 16(1): 93-99.

O’Neill, R. V. \& De Angelis, D. L. 1980. Comparative productivity and biomass relations of forest ecosystems. In: Reichle, D. L. (ed.). Dynamic properties of forest ecosystems. Cambridge, Cambridge Univ. Pr. Pp. 441-449.

Prazeres, S. M.; Silva, M. F. A.; Nazário, F. G. G. \& Souza, C. M. R. 1998. Produção, acúmulo e decomposição de serapilheira da vegetação escleromorfa (Cerradão) e subxerófila (Carrasco) na Chapada do Araripe. Crato - CE. In: Congresso Nacional de Botânica, XLIX. Anais, Salvador. Pp. 312-313.

Rosén, K. 1990. Keynote paper: measuring nutrient input to terrestrial ecosystems. In: Harrison, A. F.; Ineson, P. \& Heal, O. W. (eds.). Nutrient cycling in terrestrial ecosystems. Field methods, application and interpretation. Elsevier Applied Science. Pp. 1-10.

Sanchez, J. A. \& Sada, S.G. 1993. Litterfall dynamics in a mexican lowland tropical rain forest. Tropical Ecology 34 (2): 127-142.

Schlitter, F. H. M. 1990. Fitossociologia e ciclagem de nutrientes na floresta tropical do Parque Estadual do Morro do Diabo (Região do Pontal do Paranapanema, SP). Tese de Doutorado. Universidade de São Paulo, São Paulo, 279p. 
Thornthwaite, C. W. 1948. An approach toward a rational classification of climate. Geog. Rev. 94: 38-55.

Veneklaas, E. J. 1991. Litterfall and nutrients fluxes in two montane tropical rain forests, Colombia. Journal of Tropical Ecology 7: 319-336.
Vitousek, P. M. 1984. Litterfall, nutrient cycling, and nutrient limitation in tropical forests. Ecology 65(1): 285-298.

Vitousek, P. M. \& Sanford, R. L. 1986. Nutrient cycling in moist tropical forest. Annual Review of Ecology and Systematics 17: 137-167. 